\title{
Pengembangan Media Pembelajaran Menggunakan Construct 2 Pada Materi Relasi dan Fungsi Untuk Kelas VIII SMP
}

\author{
Beby Meidhita Syam, Nur Izzati \\ Program Studi Pendidikan Matematika, Universitas Maritim Raja Ali Haji, \\ Jl. Politeknik Senggarang, Tanjungpinang 29111, Indonesia \\ meidhitabeby@yahoo.com
}

\begin{abstract}
This study aims to develop a learning media by using construct 2 to the material of relations and functions. The type of research is research and development with the $4 D$ model were define, design, development, and disseminate. The subjects of this study were students of class VIII F Junior High School 3 Bintan amounting to 32 people in the 2019/2020 academic year. The research data was collected by using a validation technique involving 2 expert validators, each material expert and media expert, also collected by a questionnaire responding from educators and students. The research instrument consisted of validation sheets and questionnaire sheets. The research data were analyzed by changing ordinal data into interval data with the rating scale technique. The percentage of acquisition is calculated to get the category of validity and practicality. The results of this study based on the validation of material experts obtained $88.23 \%$ are in very valid criteria and validation of media experts obtained $83.33 \%$ are in very valid criteria. The response by students obtained $88.84 \%$ are in very practical criteria and from educators obtained $91.67 \%$ are in very practical criteria.
\end{abstract}

Keywords : Development; Construct 2; Relations; Functions;

is is an open access article distributed under the Creative Commons 4.0 Attribution License, which permits unrestricted use, distribution, and reproduction in any medium, provided the original work is properly cited. $\bigcirc 2018$ by author and Universitas Negeri Padang.

\section{PENDAHULUAN}

Matematika adalah ilmu pokok yang ber peran penting di kehidupan manusia serta dalam pengembangan ilmu pengetahuan dan teknologi (IPTEK). Mardiah (2018:3), mengatakan bahwa matematika adalah ilmu dasar dari ilmu lain, sehingga matematika saling berkaitan dengan ilmu lain. Matematika merupakan ilmu yang menggunakan nalar sehingga tak sedikit peserta didik yang mengaku kesulitan saat belajar mate matika. Salah satu materi dalam matematika ada lah materi relasi dan fungsi. Materi relasi dan fungsi adalah materi yang mempelajari tentang hubungan dari suatu himpunan ke himpunan lainnya. Materi relasi dan fungsi adalah materi yang mempelajari tentang hubungan dari suatu himpunan ke himpunan lainnya. Menurut Rama dan (2018:4), pemahaman konsep tentang materi relasi dan fungsi sangat penting karena materi tersebut menjadi prasyarat untuk materi pelajar an matematika selanjutnya. Penyampaian materi dalam pembelajaran dapat dilakukan dengan ber bagai cara. Salah satunya dengan memanfaatkan teknologi.

Kerangka kompetensi abad 21 mengharap kan peserta didik untuk mengenal informasi, me dia, dan teknologi informasi komunikasi. Menu rut Muhtasyam (2018:3), seiring waktu berjalan,
IPTEK berkembang pesat sehingga menjadikan pendidikan sangat dipengaruhi oleh berkembang nya IPTEK. Perkembangan IPTEK yang sangat pesat membawa perubahan terhadap media pem belajaran. Hal ini berdampak pada munculnya berbagai macam bentuk media pembelajaran.

Penggunaan media pembelajaran dapat memperlancar proses belajar mengajar sehingga tercapainya tujuan pembelajaran. Hal ini selaras dengan pendapat Nursidik (2018:1), yang menye butkan bahwa dalam proses pembelajaran sangat diperlukan adanya media pembelajaran, karena media pembelajaran dapat menciptakan suasana belajar yang aktif, tidak monoton, dan menarik. Hasibuan et al. (2019:244) juga berpendapat bahwa penting bagi seorang pendidik untuk mampu mengembangkan media pembelajaran agar mendukung pembelajaran. Salah satu tekno logi yang dapat membantu penggunaan media pembelajaran ialah perangkat mobile.

Berdasarkan observasi yang dilakukan di Sekolah Menengah Pertama Negeri 3 Bintan saat semester ganjil tahun ajaran 2019/2020, pemanfaatan teknologi masih minim. Hal ini di sebabkan karena kurangnya media pembelajaran menggunakan teknologi. Minimnya penggunaan media pembelajaran juga berdampak pada menu runnya semangat peserta didik dalam mengikuti 
proses belajar mengajar di kelas. Sebaliknya, ke banyakan peserta didik memiliki smartphone se cara pribadi. Hal ini sejalan dengan pendapat Komariah et al. (2018:45), yang menyebutkan bahwa adanya potensi peserta didik membawa smartphone ke sekolah. Di sisi lain, sejauh ini se kolah belum memanfaatkan potensi ini, dimana smartphone tersebut tidak digunakan ketika pem belajaran. Selain itu, saat pembelajaran sederha na, peserta didik tampak kurang tertarik dan ti dak bersemangat sehingga mereka kurang bermi nat untuk belajar.

Smartphone merupakan salah satu perang kat mobile sebagai media pembelajaran yang la zim dikembangkan, karena smartphone terma suk perangkat yang mudah untuk dibawa kema napun. Di zaman modern seperti ini, mayoritas peserta didik mempunyai smartphone, namun masih minim penggunaannya untuk sarana pem belajaran. Mayoritas peserta didik meggunakan smartphone sebatas untuk telepon, berkirim pe san, menyalakan musik, mengakses media so sial, dan bermain. Smartphone yang banyak ter jual menggunakan sistem operasi android. An droid menyediakan wadah bagi developer untuk mengembangkan aplikasi sendiri. Menurut Setya di (2017:88), saat ini android memiliki jumlah pengguna terbesar karena memiliki berbagai ke unggulan dalam sistem operasinya.

Salah satu software yang dapat digunakan untuk membantu membuat media pembelajaran berupa aplikasi bersistem operasi android yaitu softwareconstruct 2. Construct 2 yaitu software yang didesain khusus untuk tampilan 2 dimensi. Hal ini memudahkan siapa saja dalam mengem bangkan aplikasi tanpa memerlukan coding. Muhtasyam (2018:4) menyebutkan bahwa de ngan construct 2, mengembangkan aplikasi cu kup dengan drag-and-drop. Software ini dapat dijalankan menggunakan komputer dan dapat mengkonversi projek yang sudah dikerjakan de ngan menggunakan fitur HTML5 menjadi apli kasi bersistem operasi android. Selaras dengan pendapat Yustin et al. (2016:1), dengan meng gunakan construct 2 pengembang media dapat mempublish aplikasi yang dibuat ke beberapa platform salah satunya phonegap (android).

Pengembangan aplikasi dengan sistem operasi android sebagai media pembelajaran per lu dikembangkan. Aplikasi yang dikembangkan khusus pada materi relasi dan fungsi. Hal ini di maksudkan karena tidak tersedianya media pem belajaran pada materi tersebut. Dengan adanya aplikasi ini diharapkan mampu memanfaatkan perangkat yang ada dan mempermudah proses pembelajaran di kelas karena pengembangan ap likasi menggunakan construct 2 tidak sulit dan ti dak membutuhkan sistem coding dalam penger jaannya. Untuk itu, rumusan masalah penelitian ini adalah bagaimana pengembangan media pem belajaran menggunakan construct 2 pada materi relasi dan fungsi dan bagaimana kevalidan dan kepraktisan terhadap media pembelajaran yang dikembangkan menggunakan construct 2 pada materi relasi dan fungsi? Sehingga, tujuan pene litian ini adalah mendeskripsikan pengembangan media pembelajaran menggunakan construct 2 pada materi relasi dan fungsi dan untuk menge tahui kevalidan dan kepraktisan terhadap media pembelajaran yang dikembangkan menggunakan construct 2 pada materi relasi dan fungsi.

\section{METODE PENELITIAN}

Penelitian ini merupakan penelitian dan pengembangan (research and development). $\mathrm{Ha}$ sil yang diperoleh adalah produk berupa aplikasi sebagai media pembelajaran menggunakan soft ware construct 2 pada materi relasi dan fungsi untuk kelas VIII SMP.

Penelitian dan pengembangan media pem belajaran ini menggunakan model 4D oleh Thia garajan, Semmel, dan Semmel dalam Maulana (2017:35), yaitu define, design, development, dan disseminate. Model ini digunakan karena pe nelitian dilakukan untuk memperoleh produk be rupa aplikasi. Produk ini kemudian diuji keva lidannya dengan validitas ahli dan dilakukan uji coba produk.

Tahap define dilakukan untuk menentukan keperluan dalam proses pembelajaran dan infor masi yang berkaitan dengan aplikasi yang akan dikembangkan. Pada tahap tersebut, dilakukan analisis tentang kurikulum, karakteristik peserta didik, materi atau konsep, dan tujuan pembela jaran.

Tahap design merupakan tahapan yang di lakukan untuk merancang media pembelajaran. Mendesain produk dilakukan peneliti dengan menggunakan software construct 2 untuk me ngembangkan aplikasi dengan materi relasi dan fungsi. Perancangan media pembelajaran ini di lakukan dengan membuat dan menyusun story board. Storyboard menurut Nurrahma (2018: 29), desain gambar yang disusun secara berurut sesuai dengan alur cerita. Storyboard memudah kan peneliti dalam menuangkan ide cerita dan mendeskripsikan rancangan produk. 
Tahap development bertujuan menghasil kan aplikasi yang telah dinilai dan diperbaiki ber dasarkan tanggapan para ahli. Apikasi yang di kembangkan menggunakan software construct 2 . Kegiatan pada tahap ini adalah membuat ran cangan meliputi pembuatan background, menumenu dan tombol-tombol dalam aplikasi, penyu sunan skenario, pemilihan suara dan menginput konten materi relasi dan fungsi ke aplikasi, per baikan berdasarkan tanggapan para ahli sebelum diujicobakan. Storyboard mempermudah develo per untuk menentukan item-item yang harus di lengkapi. Peneliti juga memanfaatkan beberapa aplikasi pendukung pengembangan seperti $m s$ word untuk tulisan, pinterest untuk background, picsart pro dan photogrid untuk mengolah back ground, menu, dan tombol, mp3 to ogg untuk mengolah musik latar, dan website 2 apk builder untuk menyimpan dalam bentuk aplikasi bersis tem operasi android.

Tahap disseminate yaitu tahap penyebar luasan media pembelajaran.Tahap ini dilakukan untuk mengenalkan dan menyebarluaskan media pembelajaran ke ruang lingkup yang lebih luas agar dapat diterapkan di berbagai tempat untuk kepentingan pendidikan.

Subjek uji coba adalah peserta didik kelas VIII F Sekolah Menengah Pertama Negeri (SM PN) 3 Bintan berjumlah 32 orang. Penelitian di laksanakan pada tahun pelajaran 2019/2020.

Teknik pengumpulan data menggunakan angket dengan instrumen penelitiannya yaitu lembar validasi ahli materi dan lembar validasi ahli media serta lembar angket respon pendidik dan lembar angket respon peserta didik terhadap kepraktisan media pembelajaran yang dikem bangkan. Data yang didapatkan dari validasi ahli dilakukan dengan memberikan skala penilaian yaitu data kualitatif berdasarkan skala likert yang dikonversikan menjadi nilai dengan skala 5 yang diadopsi dari Maimunah (2019:48), yang ditunjukkan pada Tabel 1.

Tabel 1. Skala Nilai Validasi

\begin{tabular}{|c|l|c|}
\hline $\begin{array}{l}\text { Skala } \\
\text { Nilai }\end{array}$ & Keterangan & Singkatan \\
\hline 1 & Tidak Relevan & TR \\
\hline 2 & Kurang Relevan & KR \\
\hline 3 & Cukup Relevan & CR \\
\hline 4 & Relevan & R \\
\hline 5 & Sangat Relevan & SR \\
\hline
\end{tabular}

Setelah itu, data hasil penelitian dianalisis dengan cara mentransformasi data kualitatif men jadi data kuantitatif menggunakan teknik me thod of summated ratings. Kemudian, dihitung persentase perolehannya untuk mendapatkan ka tegori tingkat kevalidan dan kepraktisannya. Teknik method of summated ratings yaitu meto de penskalaan yang menggunakan distribusi res pon sebagai dasar penentuan nilai skalanya. Ka tegori-kategori respon dalam bentuk kategori or dinal akan diletakkan pada suatu kontinum. Ja rak antara kategori-kategori respon dinyatakan oleh jarak nilai z, yaitu merupakan titik letak bagi setiap kategori respons di sepanjang suatu kontinum yang berskala interval (Azwar dalam Izzati, 2017:40). Untuk memudahkan proses perhitungan nilai masing-masing kategori untuk setiap item, Izzati (2012:97-98) menyajikannya dalam bentuk tabel sebagaimana ditunjukkan oleh Tabel 2.

Tabel 2. Proses Penentuan Skor Skala untuk Setiap Item

\begin{tabular}{|l|l|l|l|l|l|}
\hline \multirow{2}{*}{$\begin{array}{l}\text { Aspek } \\
\text { Perhitungan }\end{array}$} & \multicolumn{5}{|c|}{ Kategori Pilihan } \\
\hline & TR & KR & CR & R & SR \\
\hline Frekuensi (F) & & & & & \\
\hline Proporsi (P) = F/N & & & & & \\
\hline $\begin{array}{l}\text { Proporsi } \\
\left.\text { Kumulatif ( } \mathrm{P}_{\mathrm{k}}\right)\end{array}$ & & & & & \\
\hline $\mathrm{P}_{\mathrm{k}}$-tengah & & & & & \\
\hline $\mathrm{z}$ & & & & & \\
\hline $\mathrm{z}+\mathrm{z}^{*}$ & & & & & \\
\hline $\begin{array}{l}\text { Skor item } \\
\text { (pembulatan nilai } \\
\mathrm{Z}+\mathrm{Z}^{*} \text { ) }\end{array}$ & & & & & \\
\hline
\end{tabular}

Selanjutnya, skor yang didapat dihitung dengan menggunakan rumus mengolah data oleh Arikunto dalam Purbasari et al. (2012:5), seba gai berikut.

$$
\mathrm{P}=\frac{\Sigma \mathrm{X}}{\mathrm{N}} \times 100 \%
$$

Keterangan:

$\mathrm{P}=$ persentase skor

$\sum X=$ jumlah skor yang diperoleh

$\mathrm{N}=$ skor maksimal

Untuk menentukan kriteria validitas me dia pembelajaran yang dikembangkan untuk di gunakan dalam pembelajaran digunakan kriteria kualifikasi penilaian (Arikunto, 2009:245) yang ditunjukkan pada Tabel 3. 
Tabel 3. Kriteria Kevalidan

\begin{tabular}{|l|l|l|}
\hline $\boldsymbol{\%}$ & Kriteria & Keterangan \\
\hline $80-100$ & SangatValid & TidakRevisi \\
\hline $66-79$ & Valid & TidakRevisi \\
\hline $55-65$ & CukupValid & TidakRevisi \\
\hline $40-55$ & KurangValid & Revisi \\
\hline $30-39$ & TidakValid & Revisi \\
\hline
\end{tabular}

Angket respon yang diberikan juga berda sarkan skala likert akan tetapi yang sudah dimo difikasi. Modifikasi skala likert bertujuan untuk menghilangkan kelemahan skala dengan lima ka tegori. Modifikasi tersebut menghilangkan kate gori jawaban di tengah berdasarkan alasan beri kut: (1) kategori tersebut bermakna ganda, (2) terdapat jawaban di tengah menyebabkan kecen derungan memilih jawaban tersebut, dan (3) keti ga, maksud kategori SB-B-KB-TB adalah untuk melihat kecenderungan jawaban responden, ke arah setuju atau ke arah tak setuju.

Dengan demikian, dalam penelitian ini angket respon pendidik dan peserta didik terha dap aplikasi berisi pernyataan tertutup dengan skala 4 yang dimodifikasi berdasarkan penelitian Cahyaningtyas (2018:69), berupa jawaban: $\mathrm{SB}=$ Sangat Baik dengan nilai $4, \mathrm{~B}=$ Baik dengan nilai $3, \mathrm{~KB}=$ Kurang Baik dengan nilai 2, dan $\mathrm{TB}=$ Tidak Baik dengan nilai 1 . Data yang dipe roleh berupa data kualitatif yang juga dikonversi menjadi data kuantitatif dan diolah melalui tek nik method of summated ratings. Berikut adalah kriteria hasil angket (Lestari, 2017:66), terhadap kepraktisan aplikasi yang dikembangkan.

Tabel 4. Kriteria Kepraktisan

\begin{tabular}{ll}
\hline$\%$ & Kriteria \\
\hline $76-100$ & Sangat Praktis \\
$51-75$ & Praktis \\
$26-50$ & Kurang Praktis \\
$0-25$ & Tidak Praktis \\
\hline
\end{tabular}

\section{HASIL DAN PEMBAHASAN}

\section{Tahap Define}

Pada tahap ini, hasil yang ditemukan yai tu melalui wawancara, rendahnya semangat pe serta didik dalam belajar matematika dikarena kan peserta didik berpikiran bahwa matematika itu membosankan. Pada hasil ulangan harian 1 materi relasi dan fungsi, nilai peserta didik kelas VIII memperoleh nilai rata-rata 60,5 yang ber arti belum memenuhi standar yang ditetapkan se kolah yaitu 62 dari 100. Selain itu, model pem belajaran konvensional yang diterapkan pendi dik di dalam kelas membuat sebagian peserta di dik bersikap tidak aktif sehingga menyebabkan suasana belajar yang kurang kondusif. Sedang kan melalui observasi, ditemukan bahwa tidak tersedianya perangkat pembelajaran khususnya pada materi relasi dan fungsi yang dapat diguna kan untuk menunjang pembelajaran karena pen didik menerapkan pembelajaran konvensional dengan metode ceramah.

Selain itu, pemanfaatan perangkat tekno logi seperti komputer yang terdapat di sekolah juga tidak maksimal. Penggunaan perangkat mo bile berupa smartphone juga kurang diman faatkan dalam pembelajaran padahal hampir selu ruh peserta didik memilikinya. Hal ini sangat disayangkan karena di abad 21 dan kurikulum 2013 yang sudah diterapkan yaitu menuntut penggunaan teknologi yang sifatnya mempermu dah transfer of knowledge. Analisis kurikulum yang diperoleh adalah sekolah menggunakan kurikulum 2013 dengan KI-3 dan KD 3.3 untuk kelas VIII SMP. Materi yang menjadi konten pada penelitian ini adalah materi pada semester ganjil yaitu materi relasi dan fungsi. Tidak sedi kit dari peserta didik yang memiliki smartphone dan mereka sering menghabiskan waktunya ber main smartphone. Maka dari itu media pembela jaran yang mampu menarik perhatian peserta di dik seharusnya dapat diakses melalui smartpho ne yang mereka miliki.

\section{Tahap Design dan Development}

Tahap design yang dilakukan peneliti dila kukan dengan membuat background, lalu mem buat menu-menu dan tombol-tombol, setelah itu memasukkan konten berupa materi, sejarah sing kat, latihan soal, dan identitas pengembang serta menambahkan musik latar. Rancangan tampilan aplikasi terdiri dari: (1) Halaman intro, (2) Menu Utama, (3) KI, KD, IPK, dll., (4) Sejarah singkat mengenai penemu awal konsep fungsi, (5) Mate ri yang terdiri dari relasi, fungsi, dan korespon densi satu-satu, (6) Latihan soal, dan (7) Profil peneliti sekaligus sebagai pengembang aplikasi media pembelajaran tersebut serta (8) Navigasi.

Berikut ini adalah beberapa tampilan apli kasi yang dikembangkan. Gambar 1 adalah ha laman intro yang merupakan halaman awal atau cover aplikasi, sebelum masuk ke halaman menu utama. Halaman intro memuat judul dari materi yang dipilih yaitu relasi dan fungsi. Terdapat tombol "Get Started" untuk beralih ke halaman berikutnya. 


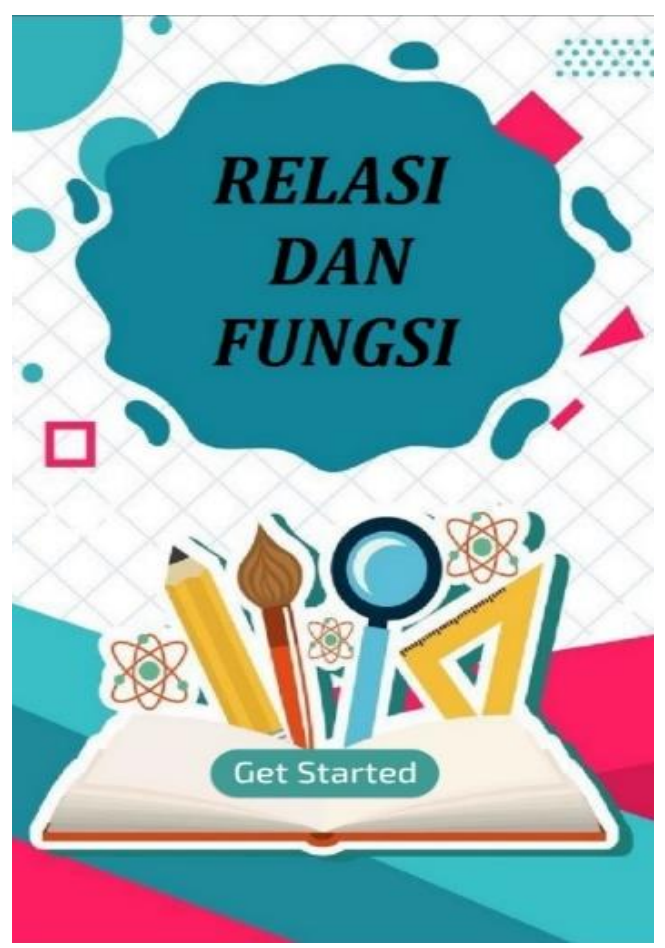

Gambar 1. Halaman Intro

Gambar 2 merupakan halaman menu uta ma dari tombol di tengah yang berisi menu-me nu berupa materi yaitu menu relasi, menu fung si, dan menu korespondensi satu-satu. Desain pa da halaman menu ini dikembangkan dengan se derhana agar peserta didik mudah mengguna kannya. Setiap materi dapat diakses dengan me nekan ikon materi yang ingin dipelajari.

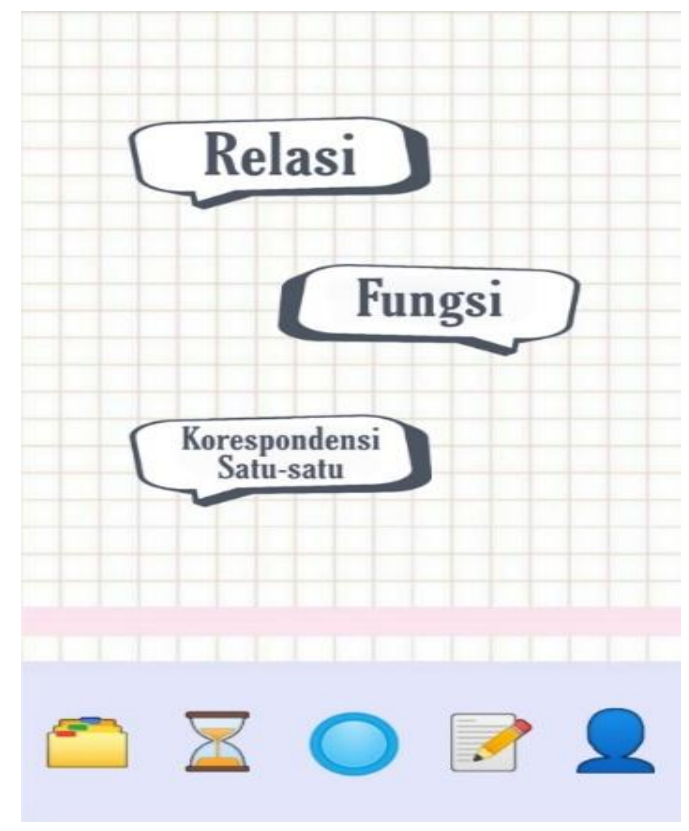

Gambar 2. Halaman Menu Utama

Halaman menu utama memuat tiga menu, yaitu relasi, fungsi dan korespondensi satu-satu.
Jika menu relasi diklik maka akan muncul mate ri tentang definisi relasi, bentuk penyajian relasi, dan contoh-contoh dari relasi. Gambar 3 adalah salah satu contoh dari tampilan isi menu relasi yaitu definisi relasi.

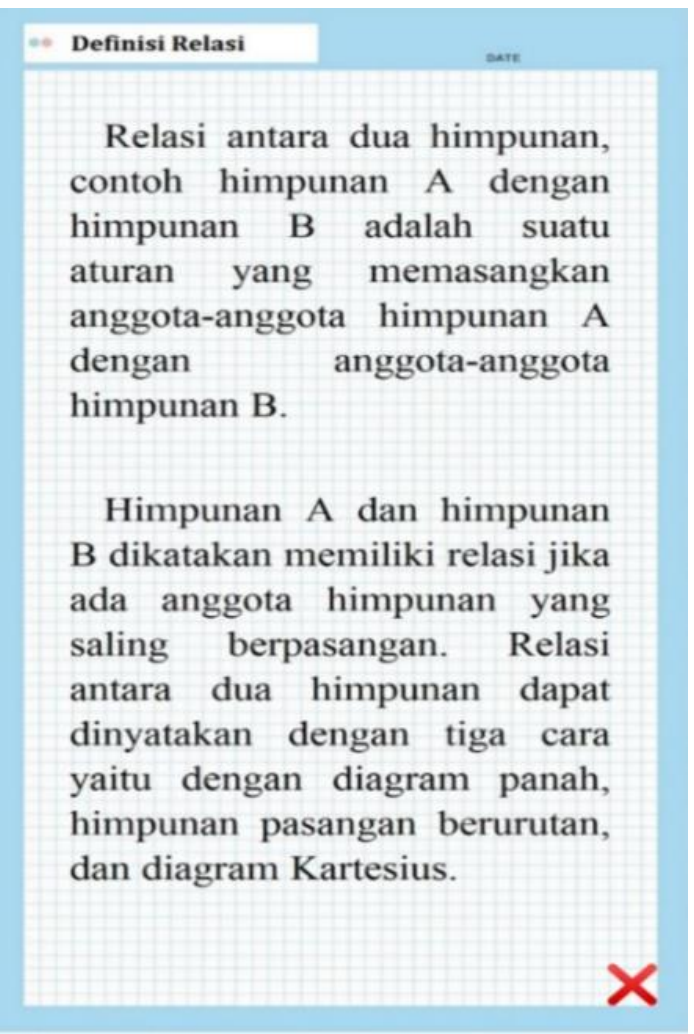

\section{Gambar 3. Definisi Relasi}

Selanjutnya, menu fungsi yang memuat definisi fungsi, bentuk penyajian fungsi, dan contoh-contoh dari fungsi. Menu ketiga adalah korespondensi satu-satu yang berisi penjelasan tentang korespondensi satu-satu, bentuk kores pondensi satu-satu, dan contoh dari korespon densi satu-satu. Salah satu contoh dari tampilan isi menu korespondensi satu-satu berupa penje lasan dan bentuk korespondensi satu-satu disaji kan pada Gambar 4.

Gambar 5 merupakan tampilan menu pa ling kiri yang berisi menu KI, KD, IPK, penga laman belajar, peta konsep, dan kata kunci yang menjadi poin-poin penting dalam materi relasi dan fungsi. Hal ini bertujuan agar peserta didik mengetahui kompetensi yang harus dicapai dari belajar materi relasi dan fungsi.

Aplikasi ini juga memuat menu tentang sejarah penemuan awal konsep fungsi sehingga lahir materi relasi dan fungsi. Hal ini bertujuan untuk menambah pengetahuan tentang matema tikawan yang berjasa dalam materi tersebut serta tak lupa untuk menghargai jasanya tersebut. 


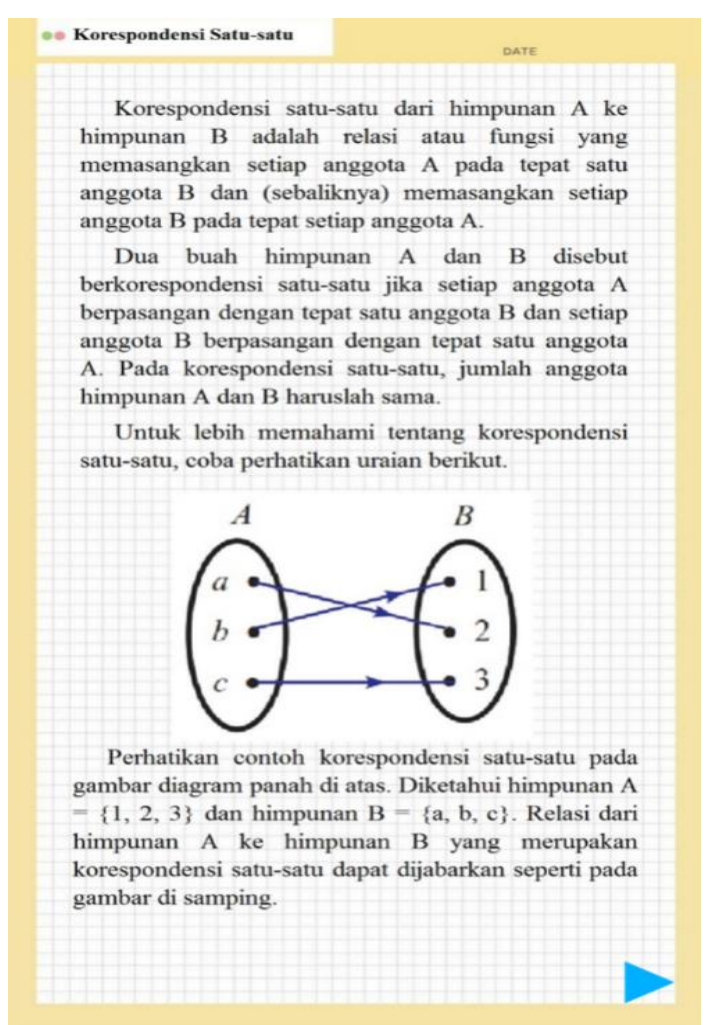

Gambar 4. Korespondesi Satu-Satu

Pada aplikasi yang telah dikembangkan, didapatkan hasil uji validitas produk melalui va lidasi para ahli. Para ahli yang melakukan vali dasi terdiri dari 2 orang pendidik di SMPN 3 Bin tan yaitu guru matematika kelas VIII sebagai ah li materi dan guru TIK sebagai ahli media.

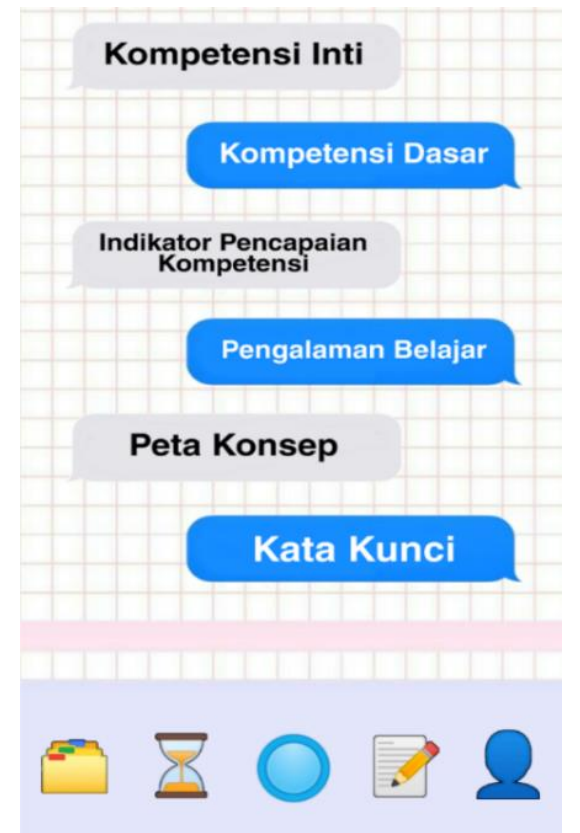

\section{Gambar 5. Halaman Menu Kompetensi}

Guru matematika menjadi ahli materi kare na guru tersebut memahami kompetensi yang ter dapat di tempat penelitian sedangkan guru TIK menjadi ahli media karena guru tersebut mema hami tek nologi serta desain yang sesuai untuk peserta didik SMP kelas VIII. Untuk validasi ah li materi bertujuan untuk mengetahui kevalidan materi relasi dan fungsi dan setelah diolah dida patkan persentase yaitu $88,23 \%$ dengan kriteria sangat valid sehingga tidak revisi. Selanjutnya kedua validasi ahli media bertujuan untuk me ngetahui kevalidan media pembelajaran yang dikembangkan pada materi relasi dan fungsi dan setelah diolah didapatkan persentase yaitu $83,33 \%$ dengan kriteria sangat valid sehingga tidak revisi.

Berdasarkan hasil penilaian para ahli ter kait kevalidan aplikasi yang dikembangkan, di peroleh rata-rata persentasenya sebesar $85,78 \%$, dengan kriteria sangat valid sehingga tidak revi si. Secara rinci tingkat kevalidan produk yang di kembangkan berdasarkan penilaian para ahli da pat dilihat pada Tabel 5.

Tabel 5. Hasil Validitas Produk

\begin{tabular}{|l|l|l|l|}
\hline Validasi & $\mathbf{\%}$ & Kriteria & Keterangan \\
\hline Ahli Materi & 88,23 & Sangat Valid & Tidak Revisi \\
\hline Ahli Media & 83,33 & Sangat Valid & Tidak Revisi \\
\hline Rata-rata & 85,78 & Sangat Valid & Tidak Revisi \\
\hline
\end{tabular}

Uji coba produk dilaksanakan pada ming gu pertama bulan November di SMP Negeri 3 Bintan tahun pelajaran 2019/2020. Subjek ujico ba merupakan peserta didik kelas VIII F seba nyak 32 orang. Dari uji coba yang dilakukan, di dapatkan persentase skor menggunakan rumus mengolah data (1) sebesar $88,84 \%$ yang berada pada kriteria sangat praktis. Sedangkan untuk respon dari pendidik, peneliti menguji cobakan kepada dua pendidik dan mendapat persentase skor yaitu $91,67 \%$ berkriteria sangat praktis. Ma ka, dari segi kepraktisan media pembelajaran memperoleh persentase skor yaitu $90,3 \%$ berkri teria sangat praktis.

\section{Tahap Disseminate}

Tahap ini dilakukan dengan menyebarluas kan media pembelajaran melalui aplikasi sha ring seperti bluetooth karena aplikasi yang di kembangkan menghasilkan produk dengan for mat .apk. Tahap ini dilakukan ke peserta didik kelas lain pada sekolah yang sama yaitu kelas VIII D dan E di SMPN 3 Bintan tahun pelajaran 2019/2020. Hasil yang didapat yaitu respon se cara langsung peserta didik yang baik setelah menggunakan aplikasi. Peserta didik mengapre siasi aplikasi tersebut dengan dilakukannya peng 
gunaan aplikasi secara bersama di dalam kelas yang diawasi oleh guru matematika.

Peneliti tidak melakukan penerapan ke ruang lingkup yang lebih luas seperti sekolah lain dikarenakan produk yang dihasilkan sudah dilakukan uji validitas oleh para ahli dan sudah diujicobakan pada peserta didik dengan hasil bahwa media pembelajaran berupa aplikasi yang telah dikembangkan sangat valid dan sangat praktis.

\section{KESIMPULAN}

Media pembelajaran yang dikembangkan berupa aplikasi yang dapat dioperasikan menggu nakan smartphone pada materi relasi dan fungsi. Aplikasi ini dikembangkan menggunakan softwa re construct 2 melalui empat tahapan, yaitu defi $n e$, design, development, dan disseminate. Berda sarkan penilaian ahli media dan ahli media, apli kasi yang dikembangkan termasuk kategori sa ngat valid, dengan persentase penilaian masingmasing ahli adalah $88,23 \%$ dan $83,33 \%$.

Berdasarkan hasil angket respon peserta didik didapatkan skor dengan persentase sebesar $88,84 \%$ dengan kriteria sangat praktis dan hasil angket respon pendidik didapatkan skor dengan persentase sebesar 91,67\% dengan kriteria sa ngat praktis. Maka, dari segi kepraktisan media pembelajaran memperoleh rata-rata persentase skor sebesar 90,3\% dengan kriteria sangat prak tis. Dengan demikian, aplikasi yang dikembang kan sangat valid dan sangat praktis untuk diman faatkan sebagai media pembelajaran.

\section{DAFTAR PUSTAKA}

Arikunto, S. (2009). Dasar-dasar Evaluasi Pen didikan. Jakarta: Bumi Aksara.

Cahyaningtyas, A. W. (2018). Pengembangan Media Pembelajaran Interaktif Berbasis Quantum Learning untuk Meningkatkan Minat Belajar dan Pemahaman Konsep Fisika Peserta Didik Kelas XI SMA Negeri 1 Depok. Skripsi. Universitas Negeri Yog yakarta.

Hasibuan, A. M., Saragih, S., \& Amry, Z. (2019). Development of learning materials based on realistic mathematics education to improve problem solving ability and student learning independence. Interna tional Electronic Journal of Mathematics Education, 14(1), 243-252.

Izzati, N. (2012). Peningkatan Kemampuan Ko munikasi Matematis dan Kemandirian Bela jar Siswa SMP melalui Pendekatan Pendi dikan Matematika Realistik. Disertasi. Uni versitas Pendidikan Indonesia.

Izzati, N. (2017). Penerapan pmr pada pembela jaran matematika untuk meningkatkan ke mandirian belajar siswa smp. Jurnal Kip rah, 5(2), 30-49.

Komariah, S., Suhendri, H., \& Hakim, A. R. (2018). Pengembangan media pembelajar an matematika siswa SMP berbasis andro id. JKPM (Jurnal Kajian Pendidikan Mate matika), 4(1), 43.

Lestari, E. S. (2017). Penggunaan Media La boratorium Virtual untuk Meningkatkan Pengetahuan Prosedural Siswa pada Pokok Bahasan Sistem Ekskresi. Skripsi. Univer sitas Pasundan.

Maimunah. (2019). Pengembangan Lembar Kerja Peserta Didik Berbasis Realistic Mathematics Education dengan Konteks Kemaritiman untuk Melatih Kemampuan Pemecahan Masalah Matematis Peserta Didik SMA Kelas XI. Skripsi. Universitas Maritim Raja Ali Haji, Tanjungpinang.

Mardiah, S. (2018). Pengembangan Modul Pem belajaran Matematika Berbasis Etnomate matika menggunakan Metode Inkuiri pada Kelas VII. Skripsi. Universitas Islam Nege ri Raden Intan, Lampung.

Maulana, M. A. (2017). Pengembangan Media Pembelajaran Berbasis Leaflet pada Materi Sistem Sirkulasi Kelas XI MAN 1 Ma kassar. Skripsi. Universitas Islam Negeri Alauddin Makassar.

Muhtasyam, A. (2018). Pengembangan Media Pembelajaran Matematika Berupa Game Edukasi Berbasis Android dengan Bantuan Software Construct 2 pada Materi Aljabar. Skripsi. Universitas Islam Negeri Syarif Hidayatullah Jakarta.

Nurrahma, H. (2018). Pengembangan Gamelan (Game Matematika Petualangan) sebagai Media Tes Ulangan Harian Berbasis Soal Cerita. Skripsi. Universitas Islam Negeri Sunan Ampel Surabaya.

Nursidik, H. (2018). Pengembangan Media Pembelajaran Interaktif Berbantu Software Lectora Inspire pada Materi Relasi dan Fungsi Kelas X. Skripsi. Universitas Islam Negeri Raden Intan Lampung.

Purbasari, R. J., Kahfi, M. S., \& Yunus, M. (2012). Pengembangan aplikasi android sebagai media pembelajaran matematika 
pada materi dimensi tiga untuk siswa sma kelas x. Jurnal Pendidikan Matematika, 1(2), 3-11.

Ramadan, F. A. (2018). Pengembangan Mobile Learning "Rensi (Relasi dan Fungsi)" Berbasis Android pada Pokok Bahasan Relasi dan Fungsi sebagai Sumber Belajar Mandiri Siswa Kelas VIII SMP. Skripsi. Universitas Islam Negeri Sunan Kalijaga.
Setyadi, D. (2017). Pengembangan mobile learning berbasis android sebagai sarana berlatih mengerjakan soal matematika. Satya Widya, 33(2), 87-92.

Yustin, J. A., Sujaini, H., \& Irwansyah, M. A. (2016). Rancang bangun aplikasi game edukasi pembelajaran matematika meng gunakan construct 2. Jurnal Sistem Dan Teknologi Informasi (JUSTIN), 1(1), 1-5. 